УДК 615. 322

\title{
ФЛАВОНОИДЫ И ТРИТЕРПЕНОВЫЕ САПОНИНЫ SCABIOSA HYRCANICA STEV., ПРОИЗРАСТАЮЩЕЙ В АЗЕРБАЙДЖАНЕ
}

\author{
(ㄱ Д.Ю. Юсифова , И.С. Мовсумов \\ Азербайджанский медицинский университет, ул. Бакиханова, 23, Баку, AZ \\ 1022 (Азербайджан), e-mail: camilya@inbox.ru
}

\begin{abstract}
Продолжая исследования биологически активных веществ у представителей семейства Dipsacaceae Lindl. (Bopсянковые), впервые изучили флавоноиды и тритерпеновые сапонины надземных органов Scabiosa hyrcanica Stev. (cкабиоза гирканская), произрастающей в Азербайджане.

K роду Scabiosa L. относится около 100 видов, распространенных преимущественно в средиземноморских странах, в Средней Европе и умеренной Азии, восточной Индии и Африке, 26-28 видов - на Кавказе, 12 видов - в Азербайджане. Scabiosa hyrcanica Stev. - многолетнее травянистое растение: стебли 30-70 см высотой; венчики голубоватофиолетовые; головки довольно крупные до 30 мм в диаметре; цветет в июне-июле.

Многие представители Scabiosa L. широко применяются в народной медицине в разных странах мира. Ранее нами были выделены из подземных органов Scabiosa hyrcanica Stev. $\beta$-ситостерин, урсоловая кислота. Путем кислотного гидролиза суммы тритерпеновых сапонинов были обнаружены олеаноловая кислота и хедерагенин. Из литературных источников известно, что растения рода Scabiosa L. богаты биологически активными веществами.

Сырье (надземные части S. hyrcanica) для исследования заготовили в конце июня 2013 г. в период полного цветения на территории Зуванда Азербайджанской Республики. Из указанного сырья нами выделены и идентифицированы гиперозид $\left(5,7,3^{\prime}, 4^{\prime}-\right.$ тетрагидрокси-3-O- $\beta$-D-галактопиранозилфлавон), цинарозид $\left(5,3^{\prime}, 4\right.$ '-тригидрокси-7-O- $\beta$-Dглюкопиранозилфлавон), лютеолин-7- $\beta$-рутинозид (3.5,3',4'-тетрагидрокси-7-О- $\beta$-рутинозилфлавон). Путем кислотного гидролиза суммы тритерпеновых сапонинов были получены олеаноловая кислота (3ß-гидрокси- $\Delta^{12}-28$ карбоксиолеанен) и хедерагенин ( $3 \beta, 23$-дигидрокси- $\Delta^{12}$-карбоксиолеанен).

Ключевые слова: скабиоза гирканская, гиперозид, цинарозид, тритерпеновые сапонины.
\end{abstract}

\section{введение}

К роду Scabiosa L. относится около 100 видов, распространенных преимущественно в средиземноморских странах, в Средней Европе и умеренной Азии, восточной Индии и Африке, 26-28 видов - на Кавказе, 12 видов - в Азербайджане. Scabiosa hyrcanica Stev. - многолетнее травянистое растение: стебли 30-70 см высотой; венчики голубовато-фиолетовые; головки довольно крупные до 30 мм в диаметре; цветет в июне-июле [1].

Многие представители Scabiosa L. широко применяются в народной медицине в разных странах миpa [2]. Ранее нами были выделены из подземных органов Scabiosa hyrcanica Stev. B-ситостерин, урсоловая кислота. Кислотным гидролизом суммы тритерпеновых сапонинов получены олеаноловая кислота и хедерагенин [3]. Из литературных источников известно, что растения рода Scabiosa L. богаты биологически активными веществами [2-9].

\section{Экспериментальная часть}

Сырье (надземные части S. hyrcanica) для исследования заготовили в конце июня 2013 г. в период полного цветения на территории Зуванда Азербайджанской Республики. Для хроматографии была использована бумага марки Filtrak FN 17; в качестве системы растворителей - бутанол-1 - этанол - 25\%-ный аммиак, $10: 2: 5$ (растворитель 1); бутанол-1 - уксусная кислота - вода, $4: 1: 5$ (растворитель 2); для ТСХ

Мовсумов Исрафиль Солтан огль - профессор, доктор фармацевтических наук

Юсифова Джамиля Юсиф кызы - доцент, кандидат фармацевтических наук, e-mail: camilya @ inbox.ru использовали пластинки Sorbfil, растворитель хлороформ - этанол, 20 : 1 (растворитель 3). ИКспектры зарегистрировали на приборе Varian (США), температуру плавления и удельное вра-

\footnotetext{
* Автор, с которым следует вести переписку.
} 
щение определяли по методике [10]. Сахара в гидролизате обнаружили (после нейтрализации карбонатом бария) анилинфталатным реактивом.

0,8 кг воздушно-сухих, измельченных надземных частей S. hyrcanica исчерпывающе экстрагировали 80\%-ным этиловым спиртом Экстракты объединяли, отфильтровывали, упаривали в вакууме до водного остатка, который промывали хлороформом. К очищенному водному раствору прибавили 400 мл этилацетата, тщательно взбалтывали и оставляли на 24 ч. Образующиеся на границе двух слоев кристаллы отделяли фильтрованием, перекристаллизовывали из водного этанола, получили вещество 1.

Водный раствор (после отделения кристаллов) упаривали до сухого остатка, растворяли в 50 мл 95\%-ного этанола, через двое суток выпавшие кристаллы отделили и перекристаллизовывали из этанола, получили вещество 2.

Из маточного раствора препаративной хроматографией на бумаге получили вещество 3.

Далее маточный раствор упаривали до сухого остатка и подвергали ТСX (пластинка - Sorbfil; pacтворитель 1; детектор - 25\%-ный спиртовый раствор фосфорновольфрамовой кислоты, с последующим нагреванием). Установили, что в маточном растворе содержатся пять соединений тритерпеновой природы, условно названные нами гирканозидами А, В, С, Д и Е. Чтобы очистить тритерпеновые сапонины от сопутствующих полифенольных соединений, раствор пропустили через хроматографическую колонку $(\mathrm{d}=2$, $\mathrm{h}=40$ см), заполненную нейтральной окисью алюминия. Колонку промывали спиртом, а затем - водой до истощения. Элюаты объединили, упаривали до сухого остатка, подвергали кислотному гидролизу (7\%-ной $\mathrm{H}_{2} \mathrm{SO}_{4}, 5$ ч.). Контроль за гидролизом проводили ТСХ - растворитель 1. Гидролизат разбавляли водой, экстрагировали хлороформом. Обнаружили, что сумма агликонов состоит из двух веществ (пластинка Sorbfil; растворитель 3).

Разделение сапониновых агликонов $S$. hyrcanica проводили на хроматографической колонке $(\mathrm{d}=3$, $\mathrm{h}=50$ см), заполненной окисью алюминия II степени активности по Брокману. При элюировании колонки хлороформом после упаривания и перекристаллизации из этанола получили вещество 4. При элюировании этилацетатом после упаривания элюата и перекристаллизации из этанола получили вещество 5.

\section{Обсуждение результатов}

Вещество 1: состав $\mathrm{C}_{21} \mathrm{H}_{20} \mathrm{O}_{11}$, т.пл. $256-258^{\circ} \mathrm{C}$ (этанол), $[\alpha]_{\mathrm{D}}{ }^{20}-52^{\circ}$ (с 0,5; метанол - пиридин). УФспектры ( $\lambda_{\max }$ метанол, нм): $350,257,264 ; \mathrm{R}_{\mathrm{f}} 0,47$ (растворитель 2). При кислотном гидролизе $\left(3 \% \mathrm{H}_{2} \mathrm{SO}_{4}\right.$, 4 ч) образуется лютеолин $(64 \%)$ и в качестве моносахарида обнаруживается D-глюкоза. Вещество 1 идентифицировали как цинарозид (лютеолин-7-O- $\beta$-D-глюкопиранозид) [11].

Вешество 2: состав $\mathrm{C}_{21} \mathrm{H}_{20} \mathrm{O}_{12}$, т.пл. $234-236^{\circ} \mathrm{C}$ (этанол), $[\alpha]_{\mathrm{D}}^{20}-42^{\circ}$ (с 0,3 ; диметилформамид). УФспектры ( $\lambda_{\max }$ метанол, нм): 360, 305, 257; $\mathrm{R}_{\mathrm{f}} 0,60$, (растворитель 2). Цианидиновая проба по Брианту показывает глюкозидную природу вещества 2. При кислотном гидролизе $\left(3 \% \mathrm{H}_{2} \mathrm{SO}_{4}, 4\right.$ ч) образуется кверцетин $(63,6 \%)$ и Dгалактоза. Вещество 2 идентифицировали как гиперозид (кверцетин-3-O- $\beta$-D-галактозид) [4].

Вещество 3: состав $\mathrm{C}_{27} \mathrm{H}_{30} \mathrm{O}_{15}$, т.пл. $220-222^{\circ} \mathrm{C}$ (водный этанол), $[\alpha]_{\mathrm{D}}{ }^{20}-85^{\circ}$ (с 0,3 ; диметилформамид). $\mathrm{R}_{\mathrm{f}}$ 0,37, (растворитель 2). При полном кислотном гидролизе $\left(4 \% \mathrm{H}_{2} \mathrm{SO}_{4}, 3\right.$ ч, $\left.100{ }^{\circ} \mathrm{C}\right)$ вещества 3 обнаружили агликон - лютеолин (48\%) и 2 моносахарида - D-глюкоза и L-рамноза.

Как следует из кислотного гидролиза, вещество 3 является биозидом или дигликозидом. Поэтому его подвергали стадийному кислотному гидролизу $(0,1 \% \mathrm{HCl})$. В гидролизате после нейтрализации обнаружили моноглюкозид лютеолин-7-O- $\beta$-D-глюкозид и моносахарид - L-рамноза. Вещество 3 идентифицировали как лютеолин-7-O- $\beta$-D-глюкорамнозид (лютеолин-7- $\beta$-рутинозид) [12].

Вещество 4: состав $\mathrm{C}_{30} \mathrm{H}_{48} \mathrm{O}_{3}$, т.пл. $303-305^{\circ} \mathrm{C}$ (этанол), $[\alpha]_{D}{ }^{20}+79 \pm 2^{\circ}$ (с 1,2 ; пиридин). Реакции Сальковского и Либермана-Бурхарда положительны. На пластинке Sorbfil при детектировании с 25\%-ным спиртовым раствором фосфорновольфрамовой кислоты с последующим нагреванием обнаруживается в виде розового пятна. Смешанная проба с достоверным образцом олеаноловой кислоты не дала депрессии в температуре плавления. Вещество 4 идентифицировали как олеаноловая кислота (3ß-гидрокси- $\Delta^{12}-28$ карбоксиолеанен) [6].

Вещество 5: состав $\mathrm{C}_{30} \mathrm{H}_{48} \mathrm{O}_{4}$, т.пл. $325-327^{\circ} \mathrm{C}$ (этанол), $[\alpha]_{\mathrm{D}}{ }^{20}+80 \pm 2^{\circ}$ (с 2,6; пиридин). Реакции Сальковского и Либермана-Бурхарда показывают, что вещество 5 относится к пентациклическим тритерпеноидам. В ИК-спектре вещества 5 обнаруживаются полосы поглощения при 3400-3200 (OH-) и $1705 \mathrm{~cm}^{-1}$ (-СООН). Вещество 5 идентифицировали как хедерагенин (3ß, 23-дигидрокси- $\Delta^{12}$-карбоксиолеанен) [3].

Следует отметить, что все выделенные вещества в той или иной степени обладают фармакологическими свойствами. Как, например, гиперозид обладает кардиотоническим, желчегонным 
и гипоазотемическим свойствами $[13,14]$. Цинарозид (лютеолин-7-O- $\beta$-D-глюкопиранозид) и лютеолин $\left(5,7,3^{\prime}, 4^{\prime}-\right.$-тетрагидроксифлавон) снижают содержание холестерина и триглицеридов в крови, аорте и в ряде случаев (в опытах на животных) оказывают более эффективное противоатеросклеротическое действие, чем существующие препараты (мисклерон и цетамифен). Кроме того, цинарозид в связи с большим содержанием в представителях рода Scabiosa может быть использован для получения лютеолина, обладающим широким спектром действия [15-19].

Олеаноловая кислота наряду с урсоловой кислотой обладает выраженной биологической активностью: кардиотонической, гиполипидемической, противоатеросклеротической, гипогликемической, антимикробной, антиканцерогенной и др. [20-22].

\section{Выводы}

Впервые изучен флавоноидный и тритерпеновый состав надземных органов Scabiosa hyrcanica, произрастающей в Азербайджане. Выделены и идентифицированы гиперозид, цинарозид, лютеолин-7рутинозид, а также путем кислотного гидролиза суммы тритерпеновых сапонинов были получены олеаноловая кислота и хедерагенин.

\section{Список литературы}

1. Флора Азербайджана. Баку, 1961. Т. VIII. 688 с.

2. Растительные ресурсы СССР. Цветковые растения, их химический состав, использование. Семейства Caprifoliaceae-Plantaginaceae. Л., 1990. 326 c.

3. Юсифова Д.Ю. Тритерпеновые сапонины и $\beta$-ситостерин корней Scabiosa hyrcanica Stev., произрастающей в Азербайджане // Технологічні та біофармацевтичні аспекти створення лікарських препаратів різноі направленості діi : матер. І Міжнар. наук.-практ. інтернет-конф. Харків, 2014. 248 с.

4. Мовсумов И.С., Юсифова Д.Ю., Гараев Э.А. Флавоноиды скабиозы дваждыперистой (S. bipinnata), произрастающей в Азербайджане // Химические проблемы. 2012. №3. С. 376-380.

5. Гараев Э.А., Мовсумов И.С. Изучение химических компонентов S. micranta // Химические проблемы. 2008. №3. C. 588-589.

6. Garayev E.A., Movsumov I.S., Isayev M.I. Flavonoids and oleanolic acid from Scabiosa caucasica // Chemistry of Natural Compounds. 2008. Vol. 44. Pp. 520-521.

7. Земцова Г.А., Бандюкова В.А., Шинкаренко А.Л. Кверцетин-дигликозид из скабиозы бледно-желтой // Химико-фармацевтический журнал. 1968. Т. 2, №12. С. 29-32.

8. Даргаева Т.Д., Бругко Л.И. Кумарины скабиозы венечной // Растительные ресурсы. 1977. Т. VIII, вып. 1. С. 78-80.

9. Резанова О.И., Найдакова Ц.А. Химический состав Scabiosa comosa Fisch. ex Roem.et Schult // Растительные ресурсы. 1974. Т. Х. вып. 3. С. 379-382.

10. Государственная фармакопея СССР. М., 1987, ХІ изд. Т. 1.334 с.

11. Geissman T.A. The chemistry of Flavonoid compounds. London, New York, Paris, 1962, 666 p.

12. Теслов Л.С. Флавоноидные биозиды Campanula patula // Химия природных соединений. 1976. №3. С. $390-391$.

13. Безрук П.И., Хаджай Я.И., Королев В.Ф. К фармакологии гиперозида и кверцетина // Материалы 9-й Всесоюзной конференции фармакологов. Свердловск,1961. С. 22-23.

14. Георгиевский В.П., Комиссаренко Н.Ф., Дмитрук С.К. Биологически активные вещества лекарственных веществ. Новосибирск, 1990. 328 с.

15. Земцова Г.Н., Бандюкова В.А. Флавоноиды как лекарственные препараты // Фармация. 1982. Т. 31, №3. С. 68-70.

16. Попова Н.В., Маслова Н.Ф., Дихтерев С.И., Литвиненко В.И. Лекарственные свойства лютеолина // Фітотерапія. Часопис. 2010. №3. С. 43-48.

17. Попова Н.В., Маслова Н.Ф., Дихтярев С.И., Литвиненко В.И. Лекарственные свойства лютеолина. Сообщение 3. Перспективы использования лютеолина для лечения бронхита // Фітотерапія. Часопис. 2010. №4. С. 65-68.

18. Seelenger G., Merfort I., Wolfle U., Schempp C.M. Anti-carsinogenic effects of the flavonoid luteolin // Molecules. 2008. Vol. 13, N10. Pp. 2628-2651.

19. Seelenger G., Merfort I., Wolfle U., Schempp C. Anti-oxidant, anti-allergic activities of luteolin // Planta Med. 2008. Vol. 74, N14. Pp. 1667-1677.

20. Козлов Л.П., Кукина Т.П., Обут С.М., Овсянникова Л.Г., Покровский Л.М., Папов С.А., Сальникова О.И., Шеремет О.П. Отходы пилотной нароботки урсоловой кислоты из ягодных шротов как источник БАВ // Новые достижения в химии и химической технологии растительного сырья: материалы III Всероссийской конференции. Барнаул, 2007. Книга 2. С. 314-317.

21. Jie Liu. Oleanolic acid and ursolic acid: Research perspectives // Journal of Ethnopharmacology. 2005. Vol. 100. Pp. 92-94.

22. Jie Liu. Pharmacology of oleanolic acid and ursolic acid // Journal of Ethnopharmacology. 1995. Vol. 49. Pp. 57-68. 
Yusifova J.Y., Movsumov I.S. FLAVONOIDS AND TRITERPENOID SAPONINS OF SCABIOSA HYRCANICA STEV., GROWING IN AZERBAIJAN

Azerbaijan Medical University, Bakikhanov st., 23, Baku, AZ 1022 (Azerbaijan), e-mail: camilya@inbox.ru

Continuing researches of biologically active substances from representatives of the family Dipsacaceae Lindl. were first studied flavonoids and triterpenoid saponins of overground parts of Scabiosa hyrcanica Stev., growing in Azerbaijan.

The genus Scabiosa L. is about 100 species distributed mainly in the Mediterranean countries, Central Europe and temperate Asia, Eastern India and Africa, 26-28 species - in the Caucasus, 12 species - in Azerbaijan. Scabiosa hyrcanica Stev. a perennial herb. Stems 30-70 cm tall. Corollas are bluish purple. Bits quite large up to $30 \mathrm{~mm}$ in diameter. Blooms in JuneJuly months.

Many members of Scabiosa L. is widely used in folk medicine in different countries. We have previously isolated from the underground organs Scabiosa hyrcanica Stev. $\beta$-sitosterol, ursolic and oleanolic acid and hederagenin [3]. From the literature it is known that plants of the genus Scabiosa L. rich in biologically active substances.

Raw material (aerial parts of $S$. hyrcanica) have prepared for the study at the end of June 2013 in the period of full bloom on the territory Zuvand of the Republic of Azerbaijan. From the above raw materials we isolated and identified hyperoside (5,7,3',4'-tetrahydroxy-3-O- $\beta$-D-qalactopyranozylflavon), cinarozide (5,3',4'-trihydroxy-7-O- $\beta$-D-glucopyranozyl-

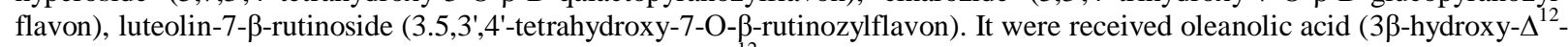
28 -carboxyoleanen) and hederagenin( $3 \beta, 23$-dihydroxy- $\Delta^{12}$-carboxyoleanen) by acid hydrolysis of amount of triterpenoid saponins.

Keywords: Scabiosa hyrcanica, hyperoside, cinarozide, triterpenoid saponins.

\section{References}

1. Flora Azerbaidzhana. [Flora of Azerbaijan]. Baku, 1961, vol. VIII, 688 p. (in Russ.).

2. Rastitel'nye resursy SSSR. Tsvetkovye rasteniia, ikh khimicheskii sostav, ispol'zovanie. Semeistva CaprifoliaceaePlantaginaceae. [Plant resources of the USSR. Flowering plants, their chemical composition, the use. Family Caprifoliaceae-Plantaginaceae]. Leningrad, 1990, 326 p. (in Russ.).

3. Iusifova D.Iu. Tehnologichni ta biofarmacevtychni aspekty stvorennja likars'kyh preparativ riznoi napravlenosti dii : mater. I Mizhnar. nauk.-prakt. internet-konf. [Technological and biopharmaceutical aspects of medicinal preparations riznoi napravlenosti actions]. Kharkiv, 2014, 248 p. (in Russ.).

4. Movsumov I.S., Iusifova D.Iu., Garaev E.A. Khimicheskie problemy, 2012, no. 3, pp. 376-380. (in Russ.).

5. Garaev E.A., Movsumov I.S. Khimicheskie problemy, 2008, no. 3, pp. 588-589. (in Russ.).

6. Garayev E.A., Movsumov I.S., Isayev M.I. Chemistry of Natural Compounds, 2008, vol. 44, pp. 520-521.

7. Zemtsova G.A., Bandiukova V.A., Shinkarenko A.L. Khimiko-farmatsevticheskii zhurnal, 1968, vol. 2, no. 12, pp. 29-32. (in Russ.).

8. Dargaeva T.D., Brutko L.I. Rastitel'nye resursy, 1977, vol. VIII, issue 1, pp. 78-80. (in Russ.).

9. Rezanova O.I., Naidakova Ts.A. Rastitel'nye resursy, 1974, vol. X, issue 3, pp. 379-382. (in Russ.).

10. Gosudarstvennaia farmakopeia SSSR. [State-owned Pharmacopoeia USSR]. Moscow, 1987, XI ed. vol. 1, 334 p. (in Russ.).

11. Geissman T.A. The chemistry of Flavonoid compounds. London, New York, Paris, 1962, 666 p.

12. Teslov L.S. Khimiia prirodnykh soedinenii, 1976, no. 3, pp. 390-391. (in Russ.).

13. Bezruk P.I., Khadzhai Ia.I., Korolev V.F. Materialy 9-i Vsesoiuznoi konferentsii farmakologov. [Articles 9 Union Conference pharmacologists]. Sverdlovsk, 1961, pp. 22-23. (in Russ.).

14. Georgievskii V.P., Komissarenko N.F., Dmitruk S.K. Biologicheski aktivnye veshchestva lekarstvennykh veshchestv. [Biologically active substances of drugs]. Novosibirsk, 1990, 328 p. (in Russ.).

15. Zemtsova G.N., Bandiukova V.A. Farmatsiia, 1982, vol. 31, no. 3, pp. 68-70. (in Russ.).

16. Popova N.V., Maslova N.F., Dikhterev S.I., Litvinenko V.I. Fitoterapija. Chasopys, 2010, no. 3, pp. 43-48. (in Russ.).

17. Popova N.V., Maslova N.F., Dikhterev S.I., Litvinenko V.I. Fitoterapija. Chasopys, 2010, no. 4, pp. 65-68. (in Russ.).

18. Seelenger G., Merfort I., Wolfle U., Schempp C.M. Molecules, 2008, vol. 13, no. 10, pp. 2628-2651.

19. Seelenger G., Merfort I., Wolfle U., Schempp C. Planta Med., 2008, vol. 74, no. 14, pp. 1667-1677.

20. Kozlov L.P., Kukina T.P., Obut S.M., Ovsiannikova L.G., Pokrovskii L.M., Papov S.A., Sal'nikova O.I., Sheremet O.P. Novye dostizheniia v khimii i khimicheskoi tekhnologii rastitel'nogo syr'ia: materialy III Vserossiiskoi konferentsii. [Advances in chemistry and chemical technology of vegetable raw materials: materials of III All-Russia conference]. Barnaul, 2007, part 2, pp. 314-317. (in Russ.).

21. Jie Liu. Journal of Ethnopharmacology, 2005, vol. 100, pp. 92-94.

22. Jie Liu. Journal of Ethnopharmacology, 1995, vol. 49, pp. 57-68.

Received September 25, 2014

Revised April 17, 2015

\footnotetext{
* Corresponding author.
} 